\title{
Manipulation of the Mononuclear Phagocyte System by Mycobacterium tuberculosis
}

\author{
Geanncarlo Lugo-Villarino ${ }^{1,2}$ and Olivier Neyrolles ${ }^{1,2}$ \\ ${ }^{1}$ Centre National de la Recherche Scientifique (CNRS), Institut de Pharmacologie et de Biologie Structurale \\ (IPBS), 31000 Toulouse, France \\ ${ }^{2}$ Université de Toulouse, Université Paul Sabatier, Institut de Pharmacologie et de Biologie Structurale \\ (IPBS), 31000 Toulouse, France \\ Correspondence: olivier.neyrolles@ipbs.fr
}

Over the past 20 years, there has been an emerging appreciation about the role of the mononuclear phagocyte system (MPS) to control and eradicate pathogens. Likewise, there have been significant advances in dissecting the mechanisms involved in the microbial subversion of MPS cells, mainly affecting their differentiation and effector functions. Mycobacterium tuberculosis is a chronic bacterial pathogen that represents an enigma to the field because of its remarkable ability to thrive in humans. One reason is that M. tuberculosis renders a defective MPS compartment, which is perhaps the most ingenious strategy for survival in the host given the prominence of these cells to modulate microenvironments, their function as sentinels and orchestrators of the immune response, and their pathogenic role as reservoirs for microbial persistence. In this article, the principal strategies used by M. tuberculosis to subvert the MPS compartment are presented along with emerging concepts.

\begin{abstract}
As part of the constant evolutionary process Ataking place in all living organisms, microbes have evolved strategies to circumvent the host immune response. Among these, the ability of Mycobacterium tuberculosis to influence the differentiation, maturation, and activation programs of the mononuclear phagocyte system (MPS) is perhaps the best strategy to avoid challenges posed by a dedicated immune response. The main reason is that the MPS not only has a prominent role in maintaining body homeostasis, but it is also critical for multiple immune-related functions. This includes the monitoring of, and interaction with, the differ-
\end{abstract}

ent local microenvironments, establishing symbiotic relationships between the host and local microbiota, recognition and capture of pathogens, activation of early defensive mechanisms of inflammation and innate effector cells, relay of innate information signals to the adaptive immune system resulting in immunological memory, and establishment of peripheral tolerance (van Furth and Cohn 1968; Gordon and Taylor 2005; Geissmann et al. 2010; Chow et al. 2011; Murray and Wynn 2011). Indeed, cells that compose the MPS, such as monocytes, macrophages, and dendritic cells, represent ideal targets of inhibition and modulation by

Editors: Stefan H.E. Kaufmann, Eric J. Rubin, and Alimuddin Zumla

Additional Perspectives on Tuberculosis available at www.perspectivesinmedicine.org

Copyright (C) 2014 Cold Spring Harbor Laboratory Press; all rights reserved; doi: 10.1101/cshperspect.a018549

Cite this article as Cold Spring Harb Perspect Med 2014;4:a018549 
invading pathogens such as $M$. tuberculosis (Wiersma et al. 1996; Martino 2008; Serbina et al. 2008; Mege et al. 2011; Mihret 2012). This is a paradoxical situation because mononuclear phagocytes are immune cells specialized in the engulfment and clearance of microbes and cellular debris, and a better understanding of their subversion by $M$. tuberculosis is likely to yield substantial insights into microbe physiology and host defenses.

The purpose of this article is not to provide a comprehensive summary of the immune evasion strategies used by $M$. tuberculosis, as there are excellent reviews covering this subject (Engering et al. 2002; Flynn and Chan 2003; Alsultan et al. 2011; Dorhoi et al. 2011; Hajishengallis and Lambris 2011; Gupta et al. 2012; O'Garra et al. 2013; Russell 2013). Nor will it address in depth some of the subjects presented in this article, as other articles cover these issues in detail. Instead, this article will focus exclusively on the most important strategies and emerging concepts concerning the subversion of MPS cells by $M$. tuberculosis. This includes the bacillus' capacity to (i) interfere with vacuolar sorting and arrest phagosome maturation; (ii) avoid killing by natural phagocyte-derived products such as reactive oxygen and nitrogen species, antimicrobial peptides, and transition metals; and (iii) extract essential nutrients from its host's cells and tissues, thus ensuring its own metabolic demands. Moreover, the modulation of macrophage polarization intertwining hallmark metabolic processes and the manipulation of dendritic cell differentiation and activation via the subversion of receptor cross talk will be presented in this article as emerging concepts in the ability of M. tuberculosis to shape its local environments in a way that is both permissive and immunosuppressant.

\section{PHAGOSOME MATURATION ARREST}

Upon phagocytosis by macrophages, particles are engulfed within a membrane-bound vacuole, or phagosome, that progressively matures through a series of fusion events with intracellular endocytic organelles and ultimately coalesces with the host cell lysosomes, thus forming a so-called phagolysosome (Desjardins and Griffiths 2003). The phagolysosome is an acidic, hydrolase-enriched, and oxidative hostile environment in which particles are degraded. Intracellular pathogens have evolved multiple mechanisms to circumvent phagolysosomal degradation (Sarantis and Grinstein 2012). Chief among these strategies is the ability of the tubercle bacillus to arrest phagosome maturation (Russell 2001; Philips 2008), a process that was originally discovered more than 40 years ago through electron microscopy observation of $M$. tuberculosis-infected macrophages in which lysosomes were loaded with ferritin; in this experiment, the absence of colocalization between the bacilli and the electron-dense ferritin granules was interpreted as a natural reluctance of the mycobacterial vacuole to fuse with lysosomes and mature into a phagolysosome (Armstrong and Hart 1971). Since then, numerous reports using various technologies showed that the mycobacterial phagosome is characterized by an abnormal retention of early endosomal markers, such as the small GTPase Rab5 and other Rab proteins, transferrin, and its receptor, and by the exclusion of late endosomal and lysosomal markers, such as the small GTPase Rab7 and the vacuolar proton transporter v-ATPase (Sturgill-Koszycki et al. 1994). Central to the impaired ability of the M. tuberculosis phagosome to fuse with host cell lysosomes is the reduced accumulation of phosphatidylinositol-3-phosphate (PI3P) onto the phagosome membrane and the resulting diminished enrichment of the vacuole in PI3Pbinding proteins early endosomal antigen 1 (EEA1) and hepatocyte growth factor-regulated tyrosine kinase substrate (Hrs), two molecules involved in protein sorting and required for phagosome fusion with late endosomes and lysosomes (Philips 2008).

How M. tuberculosis escapes lysosomal delivery inside macrophages is still an intensive area of research. Several mycobacterial lipids and glycolipids, such as lipoarabinomannan (LAM) and trehalose dimycolate (TDM), for instance, were early shown to play a part in the ability of the tubercle bacillus to avoid phagosome-lysosome fusion (Philips 2008; Russell 
Phagocyte Function Modulation by M. tuberculosis

2011). Mycobacterial proteins and enzymes, such as the lipid phosphatase SapM and the tyrosine phosphatase PtpA, the lipoamide dehydrogenase LpdC, the metalloprotease Zmp1, the serine/threonine kinase PknG, and the PEPGRS62 protein, among others, were also involved in this process (Walburger et al. 2004; Vergne et al. 2005; Deghmane et al. 2007; Bach et al. 2008; Thi et al. 2013). Additional microbial components identified through various genetic screening approaches are also involved in impaired intracellular trafficking of mycobacteria (Pethe et al. 2004; Stewart et al. 2005; Brodin et al. 2010). Distinguishing which of these factors directly contribute to phagosome maturation arrest from those required for bacterial fitness, and whose genetic alteration might result in an aberrant microbial trafficking inside host cells, is difficult. Recently, it was shown that the secreted tyrosine phosphatase PtpA directly binds to the $\mathrm{H}$ subunit of the $\mathrm{v}$-ATPase, resulting in the dephosphorylation of vacuolar protein sorting protein 33B (VPS33B) and subsequent impairment of $v$-ATPase recruitment to the vacuole (Wong et al. 2011). It was also shown that M. tuberculosis uses its type VII secretion system ESX-3 to export two effector proteins-namely, EsxH and EsxG - that interact with Hrs and impair phagosome maturation through disrupting the endosomal sorting complex required for transport (ESCRT) (Mehra et al. 2013). Other mycobacterial secreted proteins are proposed to interfere with the host cell vacuolar sorting machinery, as suggested, for example, by the aberrant trafficking of a $M$. tuberculosis mutant inactivated in the alternative secretion system component SecA2 (Sullivan et al. 2012). This infers that PtpA, Esx proteins, and other mycobacterial proteins can translocate from the phagosomal lumen to the host cell cytosol, which remains to be elucidated.

\section{RESISTANCE TO INTRACELLULAR KILLING BY ROI/RNI, ANTIMICROBIAL PEPTIDES, AND TRANSITION METAL OVERLOAD}

Phagosome maturation blockade by pathogenic mycobacteria can be overcome by exogenous stimuli, including inflammatory cytokines (e.g., TNF- $\alpha$, IFN- $\gamma$, and IL-1 $\beta$ ) (Master et al. 2008), Toll-like receptor (TLR) ligands (Brightbill et al. 1999; Thoma-Uszynski et al. 2001), and vitamin D (Liu et al. 2006; Fabri et al. 2011), among others. Overall, these molecules result in forced maturation and acidification of the mycobacterial phagosome, enhancement of the production of reactive oxygen (ROI) and nitrogen (RNI) species, induction of the synthesis of antimicrobial peptides (e.g., cathelicidin), and promotion of autophagy, a process by which intracellular replication of the bacilli is impaired. Chemical manipulation of autophagy is considered a promising strategy to control mycobacterial infections (Deretic 2008; Bradfute et al. 2013). Another mechanism of microbial control by macrophages is the accumulation of transition metals (i.e., copper and zinc), up to potentially toxic levels within vacuoles. This was first reported in Escherichia coli-infected macrophages (White et al. 2009) and more recently in $M$. tuberculosis-infected cells (Wagner et al. 2005; Ward et al. 2010; Botella et al. 2011; Wolschendorf et al. 2011). Zinc and copper play vital functions in biological systems. The chemical properties of zinc (e.g., its Lewis acidity, coordination geometry, and rapid ligand exchange) allow it to form stable complexes with enzymes and proteins where it functions in catalysis or as a structural factor. The majority of zinc-containing enzymes catalyze hydrolysis or related transfer reactions, some of which are essential for cell viability. Regarding copper, because of its fast interconversion of $\mathrm{Cu}^{+}$and $\mathrm{Cu}^{2+}$, this metal species is involved in several essential biochemical processes, such as oxygen-dependent electron transport reactions. In $M$. tuberculosis, at least two enzymes require copper as cofactor, namely the SOD SodC and the cytochrome $c$ oxidase subunits $\mathrm{CtaC}$ and $\mathrm{CtaD}$.

To counteract intracellular intoxication by acid, reactive species, and transition metals, pathogenic mycobacteria have evolved a variety of sophisticated mechanisms. This includes the production of the acid resistance proteins Rv3671c, MgtC, and OmpA 2008, 2009), the antioxidant mycothiol, the oxygen and nitrogen detoxification enzymes (i.e., 
superoxide dismutases SodA and SodC), the catalase KatG, and the NADH-dependent peroxidase and peroxynitrite reductase. SodA and KatG secretion depends on the SecA2 secretion machinery, which might partially account for the reduced ability of a $\Delta \sec A 2$ mutant of M. tuberculosis to arrest phagosome maturation and replicate inside macrophages. Recently, transition metal efflux systems - namely, the P-type ATPases CtpC (Botella et al. 2011) and CtpV (Ward et al. 2010) —and the mycobacterial copper transporter MctB (Wolschendorf et al. 2011) were involved in mycobacterial virulence, indicating $M$. tuberculosis requires an intact transition metal detoxification system to thrive inside host cells. The requirement of PATPase-mediated copper resistance systems in bacterial virulence has been documented in several bacterial species (Hood and Skaar 2012), including Listeria monocytogenes, Pseudomonas aeruginosa, Streptococcus pneumoniae, and Salmonella typhimurium. Several mechanisms are proposed to explain copper ion toxicity. These mechanisms include (i) Fenton chemistry and generation of hydroxyl radicals, although this was challenged by data showing that there is no accumulation of hydroxyl radicals in copper-exposed E. coli (Macomber et al. 2007); (ii) degradation of iron-sulfur clusters in enzymes (Chillappagari et al. 2010); and (iii) replacement of other metal ion cofactors, such as zinc ions, in proteins. The exact mechanism(s) of copper toxicity in M. tuberculosis remain to be identified. The mechanism(s) of zinc ion toxicity may also include inactivation of iron-sulfur clusters (Xu and Imlay 2012) and inhibition of manganese uptake through transport competition in the bacterial perisplam (McDevitt et al. 2011). In addition, it was shown recently that P-ATPase-mediated copper export is required for copper supply to periplasmic $\mathrm{Cu}, \mathrm{Zn}$-SOD and resistance to oxidative stress in Salmonella enterica (Osman et al. 2013). Whether P-ATPases contribute to activation of the $\mathrm{Fe}^{2+}$-cofactored, and maybe $\mathrm{Mn}^{2+}$-cofactored, superoxide dismutase (SOD) SodA, and of the suggested periplasmic $\mathrm{Cu}, \mathrm{Zn}-\mathrm{SOD}$ SodC in M. tuberculosis (Padilla-Benavides et al. 2013), remains to be further investigated.

\section{NUTRIENT ACQUISITION: IRON, CARBON, AND NITROGEN}

In addition to resisting killing mechanisms by toxic compounds inside host cells, M. tuberculosis needs to acquire nutrients in order to sustain its own metabolic demands and to replicate. Considering that the mycobacterial phagosome is naturally a nutrient-poor environment, and that MPS cells are armed with nutrient deprivation machineries to further empty microbial vacuoles of nutrient sources to ultimately constrain microbial growth, the active nutrient acquisition systems described so far for M. tuberculosis are nothing short of remarkable.

One of the best examples illustrating the socalled field of nutritional immunity and nutritional virulence (i.e., the battle for nutrient acquisition between intracellular pathogens and host cells) is provided by iron. Phagocytes produce proteins that either efflux iron from intracellular microbial compartments (through the iron transporter NRAMP1/SLC11A1, for instance) or bind heme and hemoglobin (e.g., hemopexin and haptoglobin) and reduce the availability of heme as an iron source (SilvaGomes et al. 2013). To overcome iron starvation, microbial pathogens evolved sophisticated high-affinity iron acquisition mechanisms (Hood and Skaar 2012). In the case of M. tuberculosis, the bacillus produces two siderophores: the cell-associated mycobactin and the soluble exported carboxymycobactin (Luo et al. 2005). Mycobacterial mutants unable to synthesize or export siderophores are strongly attenuated in a mouse model of tuberculosis infection, underscoring the importance of efficient iron acquisition for propagation of $M$. tuberculosis. In the extracellular environment, carboxymycobactin captures $\mathrm{Fe}^{3+}$ and transfers iron to mycobactin (Gobin and Horwitz 1996) or delivers iron via the iron-regulated $\mathrm{ABC}$ transporter IrtAB (Rodriguez and Smith 2006). It is likely siderophore-binding proteins in the $M$. tuberculosis envelope further facilitate $\mathrm{Fe}^{+3}$-carboxymycobactin uptake. The mycobacterial type VII secretion system ESX-3 was shown to be necessary for growth of M. tuberculosis in 
iron-deficient medium and for utilization of exogenously added $\mathrm{Fe}^{+3}$-carboxymycobactin (Siegrist et al. 2009), suggesting components of the ESX-3 system contribute to $\mathrm{Fe}^{+3}$-carboxymycobactin uptake. Beyond siderophore-mediated iron uptake, $M$. tuberculosis captures iron from heme using a specialized hemophore (Tullius et al. 2011).

In addition to iron and other important nutritional elements, intracellular mycobacteria need to extract carbon, energy, and nitrogen from their host cells and tissues. Several studies showed how M. tuberculosis extracts carbon and energy from various sugars and fatty acids in host cells using key enzymes (e.g., the isocitrate lyases ICL1 and ICL2, the polyphosphate glucokinase PPGK, and the phosphoenolpyruvate carboxykinase PEPCK [McKinney et al. 2000; Munoz-Elias and McKinney 2005, 2006; de Carvalho et al. 2010; Marrero et al. 2010, 2013]) and how, like in other pathogens, carbon metabolism is intrinsically linked to virulence (Eisenreich et al. 2010). Moreover, $M$. tuberculosis can also exploit other lipids, such as cholesterol, to meet its carbon and energy demands (Pandey and Sassetti 2008; Griffin et al. 2012). Regarding nitrogen metabolism, we have recently reported that $M$. tuberculosis exploits the amino acid species aspartate and asparagine to acquire this essential element, and that the Asp and Asn exploitation machineries (i.e., the Asp transporter AnsP1, the Asn transporter AnsP2, and the asparaginase AnsA) are required for mycobacterial virulence (Gouzy et al. 2013, 2014). Whether immune defense mechanisms based on Asn and Asp deprivation exist in macrophages, as recently reported for another amino acid species (namely, tryptophan [Zhang et al. 2013]), will require further investigation.

\section{MACROPHAGE POLARIZATION: MODULATION OF KEY METABOLISM PATHWAYS AND EFFECTOR FUNCTIONS}

Alveolar macrophages are one of the first cell types to participate in the initial uptake of $M$. tuberculosis (O'Garra et al. 2013). Macrophages play a dual role in tuberculosis, as they are the primary host cell reservoir for M. tuberculosis and the major effector cells to eradicate this pathogen. The capacity of M. tuberculosis to modulate the host pro-inflammatory response and seize the anti-inflammatory mechanisms that ensure tissue integrity has awakened a strong interest to investigate how pathogenic infections manipulate the process of macrophage polarization (Benoit et al. 2008; Dorhoi et al. 2011; Lugo-Villarino et al. 2011; Mege et al. 2011; Murray and Wynn 2011). Macrophage polarization is a dynamic process governed by mechanisms dictating their abundance, tissue distribution, and function-in particular, the capacity to kill intracellular pathogens (Vogt and Nathan 2011; Sica and Mantovani 2012). Two programs broadly classify polarized macrophages: classical (M1) and alternative (M2). The M1 program arises from type-1 inflammatory conditions (e.g., IFN- $\gamma$ ). M1 macrophages are characterized by high production of pro-inflammatory signals and microbicidal molecules (e.g., nitric oxide, NO) and resistance against intracellular pathogens, among others. In contrast, the M2 program is a diverse response to type-2 immune signals such as IL-4 and IL-13 (M2a); immune complexes, TLR agonists, or IL-1 receptors (M2b); and immunosuppressants like IL-10 and TGF- $\beta 1$ (M2c). M2 macrophage activity includes the suppression of inflammation, eradication of extracellular pathogens, and tissue repair, among others (Martinez et al. 2009). During infection, there is a frequent shift from M1 to M2 program of macrophage polarization at the sites of inflammation that is associated with the adaptive immune transition from acute to chronic phases. This shift is a common feature following pathogenic insult that causes tissue damage and may be essential for inflammation resolution and tissue reparation (Martinez et al. 2009; Mounier et al. 2013). However, an excessive or prolonged polarization of a given program may be detrimental to the host because of potential tissue injury or contribution to pathogenesis. In fact, there is increasing evidence that pathogens may have evolved strategies to take advantage of this polarization shift of macrophages to increase their fitness in the host (Benoit et al. 2008; Dorhoi et al. 2011; Lugo-Villarino et al. 2011; Mege 
et al. 2011; Murray and Wynn 2011). In the tuberculosis context, $M$. tuberculosis not only inhibits the pro-inflammatory activation of macrophages by secreting various virulence factors (Deretic et al. 2004; Benoit et al. 2008; Mege et al. 2011; Cambier et al. 2013), but it also promotes the shift toward M2 macrophages to ensure long-term intracellular survival (Kahnert et al. 2006; Benoit et al. 2008; Mege et al. 2011; Cambier et al. 2013). Implications stemming from the perceived ability of M. tuberculosis to influence the polarization process of macrophages are numerous, including direct contributions to the evasion strategies previously discussed. Yet, for the purpose of conciseness, we will focus exclusively on the capacity of this pathogen to modulate key metabolic pathways via the polarization of macrophages and, subsequently, influence the host production of $\mathrm{NO}$ and death modality of infected cells.

Beyond the established evidence supporting the ability of $M$. tuberculosis to influence and take advantage of the metabolic state of the host cell (McKinney et al. 2000; El Kasmi et al. 2008; Gallardo-Soler et al. 2008; Pandey and Sassetti 2008; Daniel et al. 2011; Mahajan et al. 2012; Gouzy et al. 2013; Marrero et al. 2013), an emerging theme within the field of macrophage polarization is to investigate how metabolic pathways are regulated to support or direct functional changes during pathological and pathogenic processes (Cairo et al. 2011; Chawla et al. 2011; McLaren et al. 2011; Biswas and Mantovani 2012; O’Neill and Hardie 2013; Odegaard and Chawla 2013; Pearce and Pearce 2013; Russell 2013). In general, M1 and M2 macrophages are characterized by distinct metabolic states in terms of amino acid and lipid utilization, among other types of metabolism (Fig. 1). Within the realm of amino acid metabolism, it has long been known that the differential use of arginine influences the functional capacity of polarized macrophages. A competition for this amino acid as a substrate between enzymes that drive M1 (inducible NO synthase, iNOS) or M2 (Arginase1, ARG1) polarization programs determines the NO production and, consequently, the microbicidal capacity of macrophages. From the host perspective, NO pro- duction is arguably one of the most important consequences mediated by IFN- $\gamma$ polarization of macrophages, and mice deficient for NO production readily succumb to $M$. tuberculosis infection (Flynn et al. 1993). Moreover, M1 macrophages display a "fail-safe" mechanism to sustain NO production based on citrulline recycling via ASS1 (argininosuccinate synthase), which M2 macrophages lack (Qualls et al. 2012). Conversely, M2 macrophages with enhanced levels of ARG1 display a reduced NO production and increased of iron availability, arguing that the arginine metabolism influences nutrient deprivation mechanisms in place to limit microbial growth (Kahnert et al. 2006; Cairo et al. 2011). From the pathogen perspective, M. tuberculosis promotes its survival by inducing ARG1 expression through MyD88dependent signaling pathways, supporting the concept that bacillus uses metabolic means to switch the macrophage polarization in its favor (El Kasmi et al. 2008) (Fig. 1). Furthermore, M. tuberculosis induces foam cell (macrophages rich in cholesterol and other carbon sources) formation via the production of mycobacterial lipids that trigger the activation of lipid-sensing nuclear receptors including PPAR $\gamma$ (peroxisome proliferator-activated receptor $\gamma$ ), the master regulator of M2 polarization and ARG1 (Gallardo-Soler et al. 2008; Mahajan et al. 2012). Interestingly, ARG1 is associated with M2 macrophages present in human and macaque tuberculous granuloma lesions (Pessanha et al. 2012; Mattila et al. 2013), arguing that the iNOS/ARG1 polarization axis may be pertinent beyond the murine context.

In terms of the metabolism of host lipids, there is an emerging interest on the role of eicosanoid production influencing the programmed macrophage death (Behar et al. 2010). This is partly owing to the fact that, as products of the arachidonic acid signaling cascade, eicosanoids are second messengers in tumor necrosis factor (TNF)-induced apoptosis (Wolf and Laster 1999) and modulators of the oxygen species production, which are also involved in cell death (Chang et al. 1992). Interestingly, M1 macrophages are characterized by the induction of prostaglandin-endoperoxide synthase 2 
Phagocyte Function Modulation by M. tuberculosis
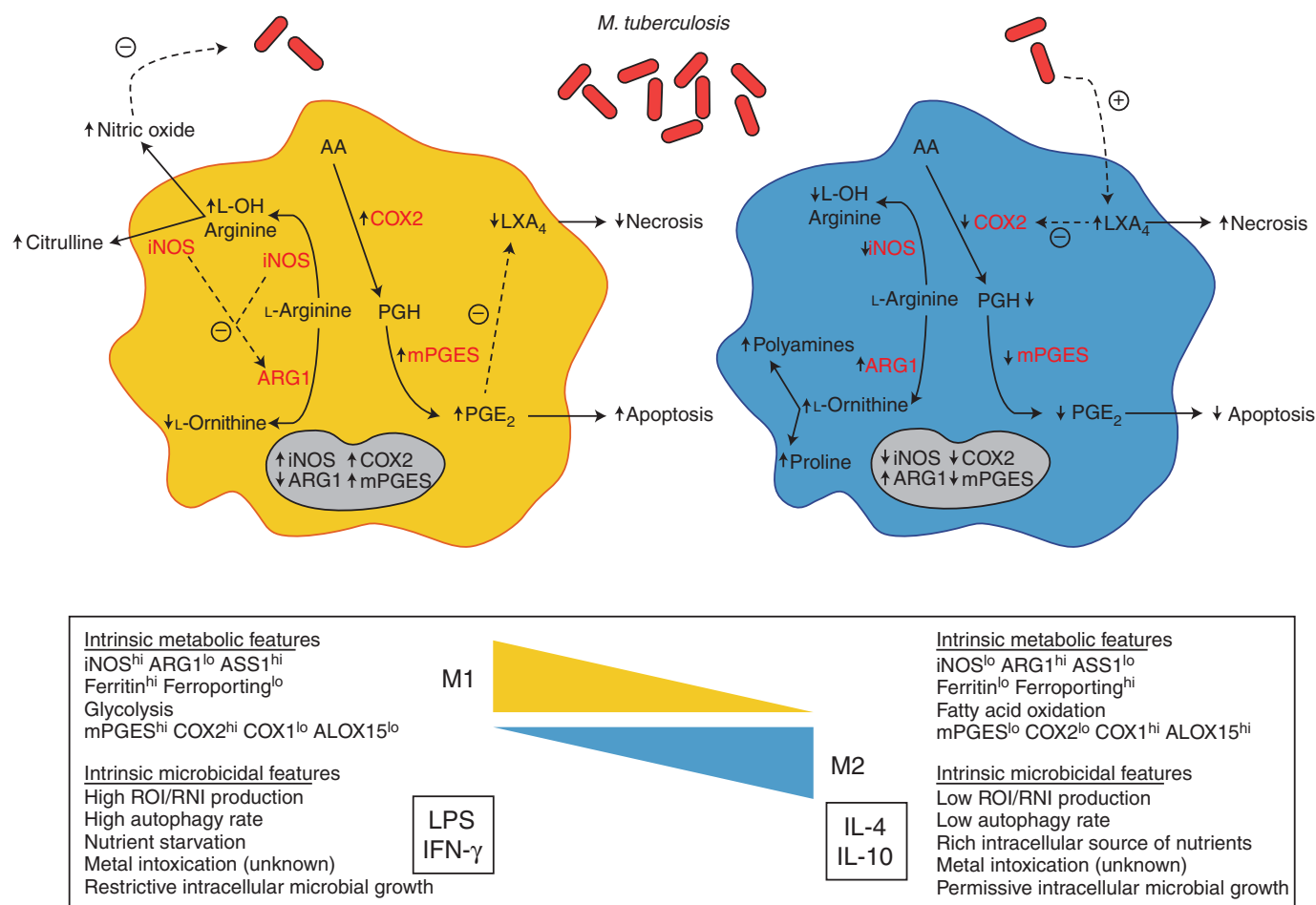

Figure 1. A model illustrating the modulation of key metabolism pathways via macrophage polarization by M. tuberculosis. On pathogenic challenge, a M1 macrophage (left) shifts its metabolic states in order to support microbicidal activities. Among these, the production of NO (nitric oxide) is an essential effector molecule to control microbial growth. To ensure an optimal NO production, M1 macrophages increase the expression ratio of iNOS (inducible NO synthase) to reduce the expression of ARG1 (arginase 1), and outcompete ARG1 for their common L-arginine substrate. In addition, as the death modality of infected macrophages is an innate immune mechanism, a M1 macrophage shifts the metabolism of arachidonic acid (AA) for the optimal production of $\mathrm{PGE}_{2}$ (Prostaglandin E2) and favors the apoptosis process, which ultimately is thought to lead to the elimination of the pathogen. This is accomplished by the increase of COX2 (prostaglandin-endoperoxide synthase 2) expression that ensures a high ratio of $\mathrm{PGE}_{2} / \mathrm{LXA}_{4}$ (lipoxin4). In contrast, a M2 macrophage (right) displays different metabolic states to support different functional programs including tissue maintenance and repair, among others. Indeed, by increasing ARG1 expression and reciprocally diminishing that of iNOS, the metabolism of L-arginine is shifted toward the production of proline and polyamines, which foment collagen production and cell proliferation, respectively. Likewise, $\mathrm{M} 2$ macrophages decrease the production $\mathrm{PGE}_{2}$ by arresting the expression of COX2. M. tuberculosis appears to have the capacity to modulate the process of macrophage polarization and influence the metabolic states of infected cells. Upon challenge with $M$. tuberculosis, the expression of ARG1 is augmented to outcompete the activity of iNOS for L-arginine and, as a consequence, diminish the production of NO. Similarly, $M$. tuberculosis also affects the AA metabolism by deliberately tilting a low ratio of $\mathrm{PGE}_{2} / \mathrm{LXA}_{4}$, driving infected macrophages toward the cell death process of necrosis, escaping intracellular defense mechanisms in a "timely" manner, and disseminating advantageously within the host.

(PTGS2, COX2) and PGE synthase (mPGES), leading to an enhanced pro-inflammatory potential exemplified by the production of prostaglandin E2 $\left(\mathrm{PGE}_{2}\right)$ (Fig. 1). Conversely, M2 macrophages display elevated levels of arachidonate 15-lipoxygenase (ALOX15) and PTGS1
(COX1), accompanied by the up-regulation of fatty acid uptake and oxidation, granting these cells an anti-inflammatory activity characterized by lipoxin A4 $\left(\mathrm{LXA}_{4}\right)$ production (Biswas and Mantovani 2012). Remarkably, the balance of the $\mathrm{PGE}_{2} / \mathrm{LXA}_{4}$ axis determines the cell 
death process of macrophages infected with M. tuberculosis (Behar et al. 2010; O'Garra et al. 2013). Indeed, driven by PTGS2 activity, the production of $\mathrm{PGE}_{2}$ prevents necrosis of infected cells and, instead, promotes apoptosis by (1) protecting the mitochondria from innermembrane damage and loss of membrane potential, (2) enabling the repair of the damage sustained by the plasma membrane, and (3) inhibiting the $\mathrm{LXA}_{4}$ production. The macrophage response to attenuated $M$. tuberculosis strains, for example, is characterized by the strong expression of PTGS2 and $\mathrm{PGE}_{2}$ production, consequently leading to high rates of apoptosis (Behar et al. 2010). In contrast, the strong production of $\mathrm{LXA}_{4}$ is known to prevent the expression of PTGS2 and production of $\mathrm{PGE}_{2}$, consequently leading to higher rates of necrosis, a situation that is reflected in the infection of macrophages with virulent strains of $M$. tuberculosis (Behar et al. 2010) (Fig. 1). In the field of host-pathogen interaction, the death modality of infected macrophages is considered an innate defense mechanism (Behar et al. 2010; Abebe et al. 2011; O'Garra et al. 2013). From the host perspective, a shift toward the M1 polarization program ensures the apoptosis of macrophages that is thought to enhance the containment of the infection, minimize tissue injury, promote the presentation of the pathogenic antigens via the cross-priming of $\mathrm{CD}^{+}{ }^{+} \mathrm{T}$ cells, and, ultimately, lead to the elimination of the pathogen. From the pathogen perspective, a shift toward the M2 polarization program promotes the necrosis of infected macrophage that consequently grants the pathogen to escape from intracellular defense mechanisms in a "timely" manner and disseminate advantageously within the host (Fig. 1).

Altogether, the iNOS/ARG1 and $\mathrm{PGE}_{2} /$ $\mathrm{LXA}_{4}$ axes best illustrate the potential of macrophage polarization to modulate key metabolic processes during the immune response, a situation that, when not properly regulated, is detrimental to the host because of potential metabolic disorders contributing to obesity, insulin resistance, diabetes, and atherosclerosis (Biswas and Mantovani 2012). Indeed, the capacity to modulate macrophage polarization and influence its metabolic states may represent only the "tip of the iceberg" concerning microbial strategies to alter the macrophage response and enhance intracellular fitness.

\section{DENDRITIC CELL DIFFERENTIATION AND ACTIVATION: MANIPULATION OF ANTI-INFLAMMATORY MEDIATORS THROUGH RECEPTOR CROSS TALK}

Besides their crucial role as the "sentinels" of the immune system, dendritic cells are also considered the "orchestrators" of the immune response because of their remarkable ability to present antigen and prime naïve $\mathrm{T}$ cells. As the most potent professional antigen-presenting cell, dendritic cells are capable of delivering three different signals that ensure the establishment of a dedicated immune response resulting in immunological memory against a given pathogenic insult: signal 1, through the processing and loading of antigenic material to be presented in the context of MHC class I and class II; signal 2, through the specific up-regulation of costimulatory molecules (e.g., CD80, CD86); and signal 3, through the optimal secretion of cytokines (e.g., IL-12) and other signaling molecules. In the context of tuberculosis, however, the interaction of M. tuberculosis with dendritic cells is not fully understood (Mihret 2012). One reason is the contradictory studies in which dendritic cells either strengthen the cellular immune response against the bacillus or contribute to pathogenesis because of a poor stimulatory activity of antigen-specific $\mathrm{CD} 4^{+} \mathrm{T}$ cells. Here, we will focus exclusively on the capacity of $M$. tuberculosis to induce anti-inflammation mediators via receptor cross talk and influence dendritic cell differentiation and functional capacity, with a particular emphasis on the immunosuppressive mediator IL-10.

As previously discussed, one of the ingenious ways to evade the host immune response is for a microbe to either prevent a dedicated pro-inflammatory response or hijack the antiinflammatory mechanisms in place to ensure host tissue integrity. The manipulation of the host receptor talk in innate immunity is an efficient microbial strategy to accomplish this 
Phagocyte Function Modulation by M. tuberculosis

(Hajishengallis and Lambris 2011). Receptor cross talk refers to the information that sentinel cells acquire from environmental clues through pattern recognition receptors (PRRs) and relay it intracellularly through nonlinear signaling cascades. In this manner, this information is integrated and processed to synergistically activate host defenses to clear infections or to antagonistically dampen unwarranted host defenses (Hajishengallis and Lambris 2011). The microbial manipulation of receptor cross talk takes place when the information to be processed is subverted or disrupted to tilt the final outcome to the microbe's favor. From the microbe perspective, subverting receptor cross talk in dendritic cells makes sense because they represent the first line of immune defense, and if properly performed, it can also undermine the overall adaptive immune response. In the context of tuberculosis, as well as with other clinical infections caused by other pathogens (e.g., Mycobacterium leprae, Helicobacter pylori, Candida albicans), the subversion of the cross talk between TLRs and the C-type lectin receptor (CLR) is thought to play a crucial role during pathogenesis (van Kooyk and Geijtenbeek 2003). By targeting the DC-SIGN (dendritic cell-specific intercellular adhesion molecule3-grabbing nonintegrin) receptor in human dendritic cells (Tailleux et al. 2003), M. tuberculosis induces the production of the immunosuppressive mediator IL-10 and, at the same time, counteracts the pro-inflammatory response driven by TLR-4 (Geijtenbeek et al. 2003). This is accomplished by mycobacterial mannosylated lipoarabinomannan (ManLAM), which binds to DC-SIGN in an autocrine or paracrine manner and foments a complex signaling cascade that leads to the phosphorylation of the p65 subunit of the transcription factor NF-кB. In fact, this posttranscriptional modification prolongs the presence of NF- $\kappa \mathrm{B}$ in the nucleus and, as a direct consequence, the augmentation of the transcription of the IL-10 gene (Geijtenbeek et al. 2003). The enhanced production of IL-10 grants multiple advantages to the invading microbe, including the inhibition of costimulatory molecules and down-regulation of IL12 in dendritic cells, ultimately tilting the adap- tive immunity in its favor from a $\mathrm{T}$ helper 1 (Th1) to a Th2 response (Redford et al. 2011; O'Garra et al. 2013).

Beyond the direct effect on dendritic cells, the modulation of anti-inflammatory mediators via receptor cross talk may also allow $M$. tuberculosis to shift the local environment in its favor and create a "bystander" effect on immune effector cells being recruited to the site of infection. For instance, it is well annotated that M. tuberculosis modulates the local environments favoring HIV-1 replication and systemic HIV-1 heterogeneity (Pawlowski et al. 2012). This bystander effect in turn leads to higher viral loads, $\mathrm{CD} 4^{+}$T-cell destruction, and higher mortality in coinfected patients. Besides the overproduction of IL-10, M. tuberculosis also promotes an environment composed of other immunosuppressive mediators such as TGF- $\beta$, Th2 cytokines (e.g., IL-4, IL-5, IL-13), deregulation of inflammatory lipids (e.g., $\mathrm{PGE}_{2}$ ), overproduction of acute-phase proteins (e.g., $\alpha 1$ acid glycoprotein), and low production of $\beta$ defensins, among others (Cooper 2009; Hernandez-Pando et al. 2009; Cooper et al. 2011; Sundareshan et al. 2011). Together, the modulation of these factors may be responsible for a bystander effect that allows $M$. tuberculosis to subvert the differentiation of monocytes into dendritic cells that are deficient in priming naïve $\mathrm{T}$ cells and, instead, contribute to pathogenic dissemination (Mariotti et al. 2002; Skold and Behar 2008; Rajashree et al. 2009). This premise is in line with the imbalance in the relative proportions of blood-circulating monocytes observed in tuberculosis patients, in which the abundance of the $\mathrm{CD} 14^{+} \mathrm{CD} 16^{+}$subset is accentuated and shown to have a defective differentiation program toward functional dendritic cells (Vanham et al. 1996; Balboa et al. 2013). In the case of IL-10, it was shown to be part of the bystander effect induced by $M$. tuberculosis to inhibit the differentiation of human monocytes into $\mathrm{CD}_{1 c^{+}}{ }^{+} \mathrm{DCs}$, suggesting it plays an important role in the recruitment of dendritic cell precursors that may be incapable to activate efficiently the adaptive immune response (Remoli et al. 2011). Supporting the concept that M. tuberculosis modulates its environment and 
the functional capacity of antigen-presenting cells in its favor, a recent study in zebrafish shows that its close pathogenic relative, Mycobacterium marinum, is able to avoid immune recognition by using cell surface-associated phthiocerol dymycoceroserate (PDIM) lipids, and at the same time, to promote the recruitment of permissive macrophages to site of infection via phenolic glycolipids (PGLs) (Cambier et al. 2013). Although the description of this study does not include the modulation of monocytes or dendritic cells by M. marinum, it can be inferred that PGLs may also be responsible for the induction of anti-inflammatory factors that modulate the recruitment of monocytes that differentiate poorly into effective antigen-presenting dendritic cells, as shown recently for $M$. tuberculosis and M. leprae (Goulart et al. 2000; Hashimoto et al. 2002).

\section{CONCLUDING REMARKS}

A tenet of this article is that further progress in the identification and characterization of microbial and host factors that are involved in macrophage polarization and key metabolic pathways during the context of microbial infection will foment a better understanding of how these processes are intertwined to influence the immune response to, and pathogenesis of, M. tuberculosis. It is anticipated that molecules that facilitate such processes are potential targets for preventive and therapeutic agents against tuberculosis. Indeed, several options are being explored for the rational design of host-directed therapies that could either reduce the destructive inflammatory responses against M. tuberculosis or augment the inadequate immunity due to virulence factors, without further fomenting the occurrence of multipledrug resistant mycobacterial strains. To accomplish this, future studies must also include efforts to bridge the knowledge obtained in the human context and from all experimental animal models, ranging from zebrafish, mouse, and guinea pig to rabbit and nonhuman primate. In addition, these studies could go along with more sophisticated "omics" global approaches to correlate transcript, protein, and metabolic content of host cells under different pathogenic contexts. Finally, it is expected that cellular and molecular mechanisms involved in preserving the tissue integrity and establishing peripheral tolerance (Medzhitov et al. 2012) might represent new venues to further investigate the ability of $M$. tuberculosis to evade and subvert the MPS compartment. Indeed, the ability of the host to tolerate a pathogen's presence is a new concept being integrated in the host-pathogen field, and one that is completely different from the host defense strategies.

\section{REFERENCES}

Abebe M, Kim L, Rook G, Aseffa A, Wassie L, Zewdie M, Zumla A, Engers H, Andersen P, Doherty TM. 2011. Modulation of cell death by M. tuberculosis as a strategy for pathogen survival. Clin Dev Immunol 2011: 678570.

Alsultan A, Giller RH, Gao D, Bathurst J, Hild E, Gore L, Foreman NK, Keating A, Quinones RR. 2011. GVHD after unrelated cord blood transplant in children: Characteristics, severity, risk factors and influence on outcome. Bone Marrow Transplant 46: 668-675.

Armstrong JA, Hart PD. 1971. Response of cultured macrophages to Mycobacterium tuberculosis, with observations on fusion of lysosomes with phagosomes. J Exp Med 134: 713-740.

Bach H, Papavinasasundaram KG, Wong D, Hmama Z, AvGay Y. 2008. Mycobacterium tuberculosis virulence is mediated by PtpA dephosphorylation of human vacuolar protein sorting 33B. Cell Host Microbe 3: 316-322.

Balboa L, Romero MM, Laborde E, Sabio YGCA, Basile JI, Schierloh P, Yokobori N, Musella RM, Castagnino J, de la Barrera S, et al. 2013. Impaired dendritic cell differentiation of CD16-positive monocytes in tuberculosis: Role of p38 MAPK. Eur J Immunol 43: 335347.

Behar SM, Divangahi M, Remold HG. 2010. Evasion of innate immunity by Mycobacterium tuberculosis: Is death an exit strategy? Nat Rev Microbiol 8: 668-674.

Benoit M, Desnues B, Mege JL. 2008. Macrophage polarization in bacterial infections. J Immunol 181: 3733-3739.

Biswas SK, Mantovani A. 2012. Orchestration of metabolism by macrophages. Cell Metab 15: 432-437.

Botella H, Peyron P, Levillain F, Poincloux R, Poquet Y, Brandli I, Wang C, Tailleux L, Tilleul S, Charriere GM, et al. 2011. Mycobacterial $\mathrm{P}_{1}$-type ATPases mediate resistance to zinc poisoning in human macrophages. Cell Host Microbe 10: 248-259.

Bradfute SB, Castillo EF, Arko-Mensah J, Chauhan S, Jiang S, Mandell M, Deretic V. 2013. Autophagy as an immune effector against tuberculosis. Curr Opin Microbiol 16: 355-365.

Brightbill HD, Libraty DH, Krutzik SR, Yang RB, Belisle JT, Bleharski JR, Maitland M, Norgard MV, Plevy SE, Smale ST, et al. 1999. Host defense mechanisms triggered by 
microbial lipoproteins through Toll-like receptors. Science 285: 732-736.

Brodin P, Poquet Y, Levillain F, Peguillet I, Larrouy-Maumus G, Gilleron M, Ewann F, Christophe T, Fenistein D, Jang J, et al. 2010. High content phenotypic cell-based visual screen identifies Mycobacterium tuberculosis acyltrehalose-containing glycolipids involved in phagosome remodeling. PLoS Pathog 6: e1001100.

Cairo G, Recalcati S, Mantovani A, Locati M. 2011. Iron trafficking and metabolism in macrophages: Contribution to the polarized phenotype. Trends Immunol 32: 241-247.

Cambier CJ, Takaki KK, Larson RP, Hernandez RE, Tobin DM, Urdahl KB, Cosma CL, Ramakrishnan L. 2013. Mycobacteria manipulate macrophage recruitment through coordinated use of membrane lipids. Nature 505: 218 222.

Chang DJ, Ringold GM, Heller RA. 1992. Cell killing and induction of manganous superoxide dismutase by tumor necrosis factor- $\alpha$ is mediated by lipoxygenase metabolites of arachidonic acid. Biochem Biophys Res Commun 188: $538-546$.

Chawla A, Nguyen KD, Goh YP. 2011. Macrophage-mediated inflammation in metabolic disease. Nat Rev Immunol 11: $738-749$.

Chillappagari S, Seubert A, Trip H, Kuipers OP, Marahiel MA, Miethke M. 2010. Copper stress affects iron homeostasis by destabilizing iron-sulfur cluster formation in Bacillus subtilis. J Bacteriol 192: 2512-2524.

Chow A, Brown BD, Merad M. 2011. Studying the mononuclear phagocyte system in the molecular age. Nat Rev Immunol 11: 788-798.

Cooper AM. 2009. Cell-mediated immune responses in tuberculosis. Annu Rev Immunol 27: 393-422.

Cooper AM, Mayer-Barber KD, Sher A. 2011. Role of innate cytokines in mycobacterial infection. Mucosal Immunol 4: $252-260$

Daniel J, Maamar H, Deb C, Sirakova TD, Kolattukudy PE. 2011. Mycobacterium tuberculosis uses host triacylglycerol to accumulate lipid droplets and acquires a dormancylike phenotype in lipid-loaded macrophages. PLoS Pathog 7: e1002093.

de Carvalho LP, Fischer SM, Marrero J, Nathan C, Ehrt S, Rhee KY. 2010. Metabolomics of Mycobacterium tuberculosis reveals compartmentalized co-catabolism of carbon substrates. Chem Biol 17: 1122-1131.

Deghmane AE, Soualhine H, Bach H, Sendide K, Itoh S, Tam A, Noubir S, Talal A, Lo R, Toyoshima S, et al. 2007. Lipoamide dehydrogenase mediates retention of coronin-1 on BCG vacuoles, leading to arrest in phagosome maturation. J Cell Sci 120: 2796-2806.

Deretic V. 2008. Autophagy, an immunologic magic bullet: Mycobacterium tuberculosis phagosome maturation block and how to bypass it. Future Microbiol 3: 517-524.

Deretic V, Vergne I, Chua J, Master S, Singh SB, Fazio JA, Kyei G. 2004. Endosomal membrane traffic: Convergence point targeted by Mycobacterium tuberculosis and HIV. Cell Microbiol 6: 999-1009.

Desjardins M, Griffiths G. 2003. Phagocytosis: Latex leads the way. Curr Opin Cell Biol 15: 498-503.
Dorhoi A, Reece ST, Kaufmann SH. 2011. For better or for worse: The immune response against Mycobacterium tuberculosis balances pathology and protection. Immunol Rev 240: 235-251

Eisenreich W, Dandekar T, Heesemann J, Goebel W. 2010. Carbon metabolism of intracellular bacterial pathogens and possible links to virulence. Nat Rev Microbiol 8: 401412.

El Kasmi KC, Qualls JE, Pesce JT, Smith AM, Thompson RW, Henao-Tamayo M, Basaraba RJ, Konig T, Schleicher U, Koo MS, et al. 2008. Toll-like receptor-induced arginase 1 in macrophages thwarts effective immunity against intracellular pathogens. Nat Immunol 9: 1399-1406.

Engering A, Geijtenbeek TB, van Kooyk Y. 2002. Immune escape through C-type lectins on dendritic cells. Trends Immunol 23: 480-485.

Fabri M, Stenger S, Shin DM, Yuk JM, Liu PT, Realegeno S, Lee HM, Krutzik SR, Schenk M, Sieling PA, et al. 2011. Vitamin D is required for IFN- $\boldsymbol{\gamma}$-mediated antimicrobial activity of human macrophages. Sci Transl Med 3: $104 \mathrm{ra} 102$.

Flynn JL, Chan J. 2003. Immune evasion by Mycobacterium tuberculosis: Living with the enemy. Curr Opin Immunol 15: $450-455$.

Flynn JL, Chan J, Triebold KJ, Dalton DK, Stewart TA, Bloom BR. 1993. An essential role for interferon $\gamma$ in resistance to Mycobacterium tuberculosis infection. J Exp Med 178: 2249-2254.

Gallardo-Soler A, Gomez-Nieto C, Campo ML, Marathe C, Tontonoz P, Castrillo A, Corraliza I. 2008. Arginase I induction by modified lipoproteins in macrophages: A peroxisome proliferator-activated receptor- $\gamma / \delta$-mediated effect that links lipid metabolism and immunity. Mol Endocrinol 22: 1394-1402.

Geijtenbeek TB, Van Vliet SJ, Koppel EA, Sanchez-Hernandez M, Vandenbroucke-Grauls CM, Appelmelk B, Van Kooyk Y. 2003. Mycobacteria target DC-SIGN to suppress dendritic cell function. J Exp Med 197: 7-17.

Geissmann F, Manz MG, Jung S, Sieweke MH, Merad M, Ley K. 2010. Development of monocytes, macrophages, and dendritic cells. Science 327: 656-661.

Gobin J, Horwitz MA. 1996. Exochelins of Mycobacterium tuberculosis remove iron from human iron-binding proteins and donate iron to mycobactins in the $M$. tuberculosis cell wall. J Exp Med 183: 1527-1532.

Gordon S, Taylor PR. 2005. Monocyte and macrophage heterogeneity. Nat Rev Immunol 5: 953-964.

Goulart IM, Mineo JR, Foss NT. 2000. Production of transforming growth factor- $\beta 1$ (TGF- $\beta 1$ ) by blood monocytes from patients with different clinical forms of leprosy. Clin Exp Immunol 122: 330-334.

Gouzy A, Larrouy-Maumus G, Wu T-D, Peixoto A, Levillain F, Gerquin-Kern J-L, de Carvalho LPS, Poquet Y, Neyrolles O. 2013. Mycobacterium tuberculosis nitrogen assimilation and host colonization require aspartate. Nat Chem Biol 9: 674-676.

Gouzy A, Larrouy-Maumus G, Bottai D, Levillain F, Wallach JB, Caire-Brandli I, de Chastellier C, Wu T-D, Poincloux R, Brosch R, et al. 2014. Mycobacterium tuberculosis exploits asparagine to assimilate nitrogen and resist acid stress during infection. PLoS Pathog 10: e1003928. 
Griffin JE, Pandey AK, Gilmore SA, Mizrahi V, McKinney JD, Bertozzi CR, Sassetti CM. 2012. Cholesterol catabolism by Mycobacterium tuberculosis requires transcriptional and metabolic adaptations. Chem Biol 19: 218227.

Gupta A, Kaul A, Tsolaki AG, Kishore U, Bhakta S. 2012. Mycobacterium tuberculosis: immune evasion, latency and reactivation. Immunobiology 217: 363-374.

Hajishengallis G, Lambris JD. 2011. Microbial manipulation of receptor crosstalk in innate immunity. Nat Rev Immunol 11: 187-200.

Hashimoto K, Maeda Y, Kimura H, Suzuki K, Masuda A, Matsuoka M, Makino M. 2002. Mycobacterium leprae infection in monocyte-derived dendritic cells and its influence on antigen-presenting function. Infect Immun 70: 5167-5176.

Hernandez-Pando R, Orozco H, Aguilar D. 2009. Factors that deregulate the protective immune response in tuberculosis. Arch Immunol Ther Exp 57: 355-367.

Hood MI, Skaar EP. 2012. Nutritional immunity: Transition metals at the pathogen-host interface. Nat Rev Microbiol 10: $525-537$.

Kahnert A, Seiler P, Stein M, Bandermann S, Hahnke K, Mollenkopf H, Kaufmann SH. 2006. Alternative activation deprives macrophages of a coordinated defense program to Mycobacterium tuberculosis. Eur J Immunol 36: 631-647.

Liu PT, Stenger S, Li H, Wenzel L, Tan BH, Krutzik SR, Ochoa MT, Schauber J, Wu K, Meinken C, et al. 2006. Toll-like receptor triggering of a vitamin $\mathrm{D}$-mediated human antimicrobial response. Science 311: 1770-1773.

Lugo-Villarino G, Verollet C, Maridonneau-Parini I, Neyrolles O. 2011. Macrophage polarization: Convergence point targeted by mycobacterium tuberculosis and HIV. Front Immunol 2: 43.

Luo M, Fadeev EA, Groves JT. 2005. Mycobactin-mediated iron acquisition within macrophages. Nat Chem Biol 1: 149-153.

Macomber L, Rensing C, Imlay JA. 2007. Intracellular copper does not catalyze the formation of oxidative DNA damage in Escherichia coli. J Bacteriol 189: 1616-1626.

Mahajan S, Dkhar HK, Chandra V, Dave S, Nanduri R, Janmeja AK, Agrewala JN, Gupta P. 2012. Mycobacterium tuberculosis modulates macrophage lipid-sensing nuclear receptors PPAR $\gamma$ and TR4 for survival. J Immunol 188: 5593-5603.

Mariotti S, Teloni R, Iona E, Fattorini L, Giannoni F, Romagnoli G, Orefici G, Nisini R. 2002. Mycobacterium tuberculosis subverts the differentiation of human monocytes into dendritic cells. Eur J Immunol 32: 3050_ 3058.

Marrero J, Rhee KY, Schnappinger D, Pethe K, Ehrt S. 2010. Gluconeogenic carbon flow of tricarboxylic acid cycle intermediates is critical for Mycobacterium tuberculosis to establish and maintain infection. Proc Natl Acad Sci 107: 9819-9824.

Marrero J, Trujillo C, Rhee KY, Ehrt S. 2013. Glucose phosphorylation is required for Mycobacterium tuberculosis persistence in mice. PLoS Pathog 9: e1003116.
Martinez FO, Helming L, Gordon S. 2009. Alternative activation of macrophages: An immunologic functional perspective. Annu Rev Immunol 27: 451-483.

Martino A. 2008. Mycobacteria and innate cells: Critical encounter for immunogenicity. J Biosci 33: 137-144.

Master SS, Rampini SK, Davis AS, Keller C, Ehlers S, Springer B, Timmins GS, Sander P, Deretic V. 2008. Mycobacterium tuberculosis prevents inflammasome activation. Cell Host Microbe 3: 224-232.

Mattila JT, Ojo OO, Kepka-Lenhart D, Marino S, Kim JH, Eum SY, Via LE, Barry CE III, Klein E, Kirschner DE, et al. 2013. Microenvironments in tuberculous granulomas are delineated by distinct populations of macrophage subsets and expression of nitric oxide synthase and arginase isoforms. J Immunol 191: 773-784.

McDevitt CA, Ogunniyi AD, Valkov E, Lawrence MC, Kobe B, McEwan AG, Paton JC. 2011. A molecular mechanism for bacterial susceptibility to zinc. PLoS Pathog 7: e1002357.

McKinney JD, Honer zu Bentrup K, Munoz-Elias EJ, Miczak A, Chen B, Chan WT, Swenson D, Sacchettini JC, Jacobs WR Jr, Russell DG. 2000. Persistence of Mycobacterium tuberculosis in macrophages and mice requires the glyoxylate shunt enzyme isocitrate lyase. Nature 406: 735-738.

McLaren JE, Michael DR, Ashlin TG, Ramji DP. 2011. Cytokines, macrophage lipid metabolism and foam cells: Implications for cardiovascular disease therapy. Prog Lipid Res 50: 331-347.

Medzhitov R, Schneider DS, Soares MP. 2012. Disease tolerance as a defense strategy. Science 335: 936-941.

Mege JL, Mehraj V, Capo C. 2011. Macrophage polarization and bacterial infections. Curr Opin Infect Dis 24: 230 234.

Mehra A, Zahra A, Thompson V, Sirisaengtaksin N, Wells A, Porto M, Koster S, Penberthy K, Kubota Y, Dricot A, et al. 2013. Mycobacterium tuberculosis type VII secreted effector EsxH targets host ESCRT to impair trafficking. PLoS Pathog 9: e1003734.

Mihret A. 2012. The role of dendritic cells in Mycobacterium tuberculosis infection. Virulence 3: 654-659.

Mounier R, Theret M, Arnold L, Cuvellier S, Bultot L, Goransson O, Sanz N, Ferry A, Sakamoto K, Foretz M, et al. 2013. AMPK $\alpha 1$ regulates macrophage skewing at the time of resolution of inflammation during skeletal muscle regeneration. Cell Metab 18: 251-264.

Munoz-Elias EJ, McKinney JD. 2005. Mycobacterium tuberculosis isocitrate lyases 1 and 2 are jointly required for in vivo growth and virulence. Nat Med 11: 638-644.

Munoz-Elias EJ, McKinney J.D. 2006. Carbon metabolism of intracellular bacteria. Cell Microbiol 8: 10-22.

Murray PJ, Wynn TA. 2011. Protective and pathogenic functions of macrophage subsets. Nat Rev Immunol 11: $723-$ 737.

O'Garra A, Redford PS, McNab FW, Bloom CI, Wilkinson RJ, Berry MP. 2013. The immune response in tuberculosis. Annu Rev Immunol 31: 475-527.

O'Neill LA, Hardie DG. 2013. Metabolism of inflammation limited by AMPK and pseudo-starvation. Nature 493: $346-355$. 
Odegaard JI, Chawla A. 2013. The immune system as a sensor of the metabolic state. Immunity 38: 644-654.

Osman D, Patterson CJ, Bailey K, Fisher K, Robinson NJ, Rigby SE, Cavet JS. 2013. The copper supply pathway to a salmonella $\mathrm{Cu}, \mathrm{Zn}$-superoxide dismutase (SodCII) involves $\mathrm{P}_{1 \mathrm{~B}}$-type ATPase copper efflux and periplasmic CueP. Mol Microbiol 87: 466-477.

Padilla-Benavides T, Long JE, Raimunda D, Sassetti CM, Arguello JM. 2013. A novel $\mathrm{P}_{1 \mathrm{~B}}$-type $\mathrm{Mn}^{2+}$-transporting ATPase is required for secreted protein metallation in mycobacteria. J Biol Chem 288: 11334-11347.

Pandey AK, Sassetti CM. 2008. Mycobacterial persistence requires the utilization of host cholesterol. Proc Natl Acad Sci 105: 4376-4380.

Pawlowski A, Jansson M, Skold M, Rottenberg ME, Kallenius G. 2012. Tuberculosis and HIV co-infection. PLoS Pathog 8: e1002464.

Pearce EL, Pearce EJ. 2013. Metabolic pathways in immune cell activation and quiescence. Immunity 38: 633-643.

Pessanha AP, Martins RA, Mattos-Guaraldi AL, Vianna A, Moreira LO. 2012. Arginase-1 expression in granulomas of tuberculosis patients. FEMS Immunol Med Microbiol 66: $265-268$.

Pethe K, Swenson DL, Alonso S, Anderson J, Wang C, Russell DG. 2004. Isolation of Mycobacterium tuberculosis mutants defective in the arrest of phagosome maturation. Proc Natl Acad Sci 101: 13642-13647.

Philips JA. 2008. Mycobacterial manipulation of vacuolar sorting. Cell Microbiol 10: 2408-2415.

Qualls JE, Subramanian C, Rafi W, Smith AM, Balouzian L, DeFreitas AA, Shirey KA, Reutterer B, Kernbauer E, Stockinger S, et al. 2012. Sustained generation of nitric oxide and control of mycobacterial infection requires argininosuccinate synthase 1. Cell Host Microbe 12: 313-323.

Rajashree P, Krishnan G, Das SD. 2009. Impaired phenotype and function of monocyte derived dendritic cells in pulmonary tuberculosis. Tuberculosis 89: 77-83.

Redford PS, Murray PJ, O'Garra A. 2011. The role of IL-10 in immune regulation during $M$. tuberculosis infection. $M u$ cosal Immunol 4: 261-270.

Remoli ME, Giacomini E, Petruccioli E, Gafa V, Severa M, Gagliardi MC, Iona E, Pine R, Nisini R, Coccia EM. 2011. Bystander inhibition of dendritic cell differentiation by Mycobacterium tuberculosis-induced IL-10. Immunol Cell Biol 89: 437-446.

Rodriguez GM, Smith I. 2006. Identification of an ABC transporter required for iron acquisition and virulence in Mycobacterium tuberculosis. J Bacteriol 188: 424-430.

Russell DG. 2001. Mycobacterium tuberculosis: Here today, and here tomorrow. Nat Rev Mol Cell Biol 2: 569-577.

Russell DG. 2011. Mycobacterium tuberculosis and the intimate discourse of a chronic infection. Immunol Rev 240: $252-268$.

Russell DG. 2013. The evolutionary pressures that have molded Mycobacterium tuberculosis into an infectious adjuvant. Curr Opin Microbiol 16: 78-84.

Sarantis H, Grinstein S. 2012. Subversion of phagocytosis for pathogen survival. Cell Host Microbe 12: 419-431.
Serbina NV, Jia T, Hohl TM, Pamer EG. 2008. Monocytemediated defense against microbial pathogens. Annu Rev Immunol 26: 421-452.

Sica A, Mantovani A. 2012. Macrophage plasticity and polarization: In vivo veritas. J Clin Invest 22: 787-795.

Siegrist MS, Unnikrishnan M, McConnell MJ, Borowsky M, Cheng TY, Siddiqi N, Fortune SM, Moody DB, Rubin EJ. 2009. Mycobacterial Esx-3 is required for mycobactinmediated iron acquisition. Proc Natl Acad Sci 106: 18792-18797.

Silva-Gomes S, Vale-Costa S, Appelberg R, Gomes MS. 2013. Iron in intracellular infection: To provide or to deprive? Front Cell Infect Microbiol 3: 96.

Skold M, Behar SM. 2008. Tuberculosis triggers a tissuedependent program of differentiation and acquisition of effector functions by circulating monocytes. J Immunol 181: 6349-6360.

Stewart GR, Patel J, Robertson BD, Rae A, Young DB. 2005. Mycobacterial mutants with defective control of phagosomal acidification. PLoS Pathog 1: 269-278.

Sturgill-Koszycki S, Schlesinger PH, Chakraborty P, Haddix PL, Collins HL, Fok AK, Allen RD, Gluck SL, Heuser J, Russell DG. 1994. Lack of acidification in Mycobacterium phagosomes produced by exclusion of the vesicular proton-ATPase. Science 263: 678-681.

Sullivan JT, Young EF, McCann JR, Braunstein M. 2012. The Mycobacterium tuberculosis SecA2 system subverts phagosome maturation to promote growth in macrophages. Infect Immun 80: 996-1006.

Sundareshan V, Modi J, Khardori NM. 2011. Mycobacteria and biological response modifiers: Two sides of the relationship. Infect Dis Clin North Am 25: 865-893.

Tailleux L, Schwartz O, Herrmann JL, Pivert E, Jackson M, Amara A, Legres L, Dreher D, Nicod LP, Gluckman JC, et al. 2003. DC-SIGN is the major Mycobacterium tuberculosis receptor on human dendritic cells. J Exp Med 197: 121-127.

Thi EP, Hong CJ, Sanghera G, Reiner NE. 2013. Identification of the Mycobacterium tuberculosis protein PEPGRS62 as a novel effector that functions to block phagosome maturation and inhibit iNOS expression. Cell Microbiol 15: 795-808.

Thoma-Uszynski S, Stenger S, Takeuchi O, Ochoa MT, Engele M, Sieling PA, Barnes PF, Rollinghoff M, Bolcskei PL, Wagner M, et al. 2001. Induction of direct antimicrobial activity through mammalian Toll-like receptors. Science 291: 1544-1547.

Tullius MV, Harmston CA, Owens CP, Chim N, Morse RP, McMath LM, Iniguez A, Kimmey JM, Sawaya MR, Whitelegge JP, et al. 2011. Discovery and characterization of a unique mycobacterial heme acquisition system. Proc Natl Acad Sci 108: 5051-5056.

van Furth R, Cohn ZA. 1968. The origin and kinetics of mononuclear phagocytes. J Exp Med 128: 415-435.

van Kooyk Y, Geijtenbeek TB. 2003. DC-SIGN: Escape mechanism for pathogens. Nat Rev Immunol 3: 697-709.

Vandal OH, Nathan CF, Ehrt S. 2009. Acid resistance in Mycobacterium tuberculosis. J Bacteriol 191: 4714-4721.

Vandal OH, Pierini LM, Schnappinger D, Nathan CF, Ehrt S. 2008. A membrane protein preserves intrabacterial $\mathrm{pH}$ in 


\section{G. Lugo-Villarino and O. Neyrolles}

intraphagosomal Mycobacterium tuberculosis. Nat Med 14: $849-854$.

Vanham G, Edmonds K, Qing L, Hom D, Toossi Z, Jones B Daley CL, Huebner B, Kestens L, Gigase P, et al. 1996. Generalized immune activation in pulmonary tuberculosis: Co-activation with HIV infection. Clin Exp Immunol 103: 30-34.

Vergne I, Chua J, Lee HH, Lucas M, Belisle J, Deretic V. 2005. Mechanism of phagolysosome biogenesis block by viable Mycobacterium tuberculosis. Proc Natl Acad Sci 102: 4033-4038.

Vogt G, Nathan C. 2011. In vitro differentiation of human macrophages with enhanced antimycobacterial activity. J Clin Invest 121: 3889-3901.

Wagner D, Maser J, Lai B, Cai Z, Barry CE 3rd, Honer Zu Bentrup K, Russell DG, Bermudez LE. 2005. Elemental analysis of Mycobacterium avium-, Mycobacterium tuberculosis-, and Mycobacterium smegmatis-containing phagosomes indicates pathogen-induced microenvironments within the host cell's endosomal system. J Immunol 174: $1491-1500$.

Walburger A, Koul A, Ferrari G, Nguyen L, PrescianottoBaschong C, Huygen K, Klebl B, Thompson C, Bacher G, Pieters J. 2004. Protein kinase G from pathogenic mycobacteria promotes survival within macrophages. Science 304: $1800-1804$.

Ward SK, Abomoelak B, Hoye EA, Steinberg H, Talaat AM. 2010. CtpV: A putative copper exporter required for full virulence of Mycobacterium tuberculosis. Mol Microbio 77: 1096-1110.
White C, Lee J, Kambe T, Fritsche K, Petris MJ. 2009. A role for the ATP7A copper-transporting ATPase in macrophage bactericidal activity. J Biol Chem 284: 3394933956.

Wiersma T, Mol SS, Thomas S. 1996. [Bone density measurement and prevention of fractures: Who should be eligible?]. Ned Tijdsch Geneeskd 140: 1622.

Wolf LA, Laster SM. 1999. Characterization of arachidonic acid-induced apoptosis. Cell Biochem Biophys 30: $353-$ 368.

Wolschendorf F, Ackart D, Shrestha TB, Hascall-Dove L, Nolan S, Lamichhane G, Wang Y, Bossmann SH, Basaraba RJ, Niederweis M. 2011. Copper resistance is essential for virulence of Mycobacterium tuberculosis. Proc Natl Acad Sci 108: 1621-1626.

Wong D, Bach H, Sun J, Hmama Z, Av-Gay Y. 2011. Mycobacterium tuberculosis protein tyrosine phosphatase (PtpA) excludes host vacuolar- $\mathrm{H}^{+}$-ATPase to inhibit phagosome acidification. Proc Natl Acad Sci 108: $19371-19376$.

Xu FF, Imlay JA. 2012. Silver(I), mercury(II), cadmium(II), and zinc(II) target exposed enzymic iron-sulfur clusters when they toxify Escherichia coli. Appl Environ Microbiol 78: 3614-3621.

Zhang YJ, Reddy MC, Ioerger TR, Rothchild AC, Dartois V, Schuster BM, Trauner A, Wallis D, Galaviz S, Huttenhower C, et al. 2013. Tryptophan biosynthesis protects mycobacteria from CD4 T-cell-mediated killing. Cell 155: 1296-1308. 


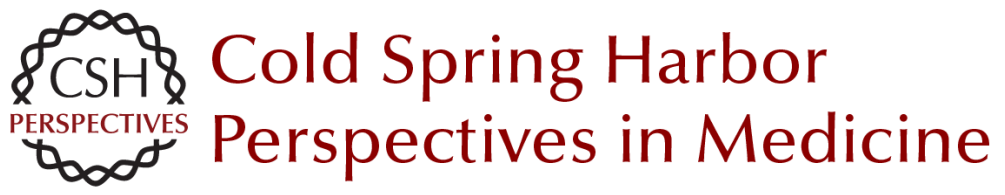

\section{Manipulation of the Mononuclear Phagocyte System by Mycobacterium tuberculosis}

Geanncarlo Lugo-Villarino and Olivier Neyrolles

Cold Spring Harb Perspect Med 2014; doi: 10.1101/cshperspect.a018549 originally published online August 21, 2014

Subject Collection Tuberculosis

Transmission and Institutional Infection Control

of Tuberculosis

Edward A. Nardell

Innate and Adaptive Cellular Immune Responses

to Mycobacterium tuberculosis Infection

Katrin D. Mayer-Barber and Daniel L. Barber

Tuberculosis Comorbidity with Communicable and Noncommunicable Diseases

Matthew Bates, Ben J. Marais and Alimuddin Zumla

Host-Directed Therapies for Tuberculosis

David M. Tobin

Immunity and Immunopathology in the

Tuberculous Granuloma

Antonio J. Pagán and Lalita Ramakrishnan

Tuberculosis Drug Development: History and Evolution of the Mechanism-Based Paradigm? Sumit Chakraborty and Kyu Y. Rhee

\section{Genetic Approaches to Facilitate Antibacterial Drug Development Dirk Schnappinger}

The Tuberculosis Drug Discovery and

Development Pipeline and Emerging Drug Targets Khisimuzi Mdluli, Takushi Kaneko and Anna Upton
Clinical Aspects of Adult Tuberculosis

Robert Loddenkemper, Marc Lipman and Alimuddin Zumla

Advances in Diagnostic Assays for Tuberculosis Stephen D. Lawn

Diagnosis and Management of Latent

Tuberculosis Infection

Laura Muñoz, Helen R. Stagg and Ibrahim Abubakar

Mycobacterial Growth

Iria Uhía, Kerstin J. Williams, Vahid Shahrezaei, et al.

Multidrug-Resistant Tuberculosis and Extensively

Drug-Resistant Tuberculosis

Kwonjune J. Seung, Salmaan Keshavjee and Michael L. Rich

The Mycobacterial Cell Wall--Peptidoglycan and

Arabinogalactan

Luke J. Alderwick, James Harrison, Georgina S. Lloyd, et al.

Tuberculosis and HIV Coinfection Judith Bruchfeld, Margarida Correia-Neves and Gunilla Källenius

Imaging in Tuberculosis Jamshed B. Bomanji, Narainder Gupta, Parveen Gulati, et al.

For additional articles in this collection, see http://perspectivesinmedicine.cshlp.org/cgi/collection/ 